\title{
The Impact of High-Rise Buildings on the Living Environment
}

\author{
Botir Giyasov ${ }^{1 *}$, Irina Giyasova ${ }^{2}$ \\ ${ }^{1}$ Moscow State University of Civil Engineering, Yaroslavskoe shosse, 26, Moscow, 129337, Russia \\ ${ }^{2}$ Tambov State Technical University, Sovetskaya St. Tambov. 392000. Russia
}

\begin{abstract}
Urbanization as a socio-economic process manifested in the concentration of the population in modern big cities contributes to the development of high-rise building construction. With the development of education and culture, changing leisure habits, city residents put forward new architectural and functional requirements to the living environment and urban infrastructure. This calls for the creation of new types and forms of residential buildings, the structure of the city and transport networks. In addition, the need to develop high-rise building construction is justified by the growing demand for residential, public and administrative buildings and the lack of free space. The paper analyzes the development of high-rise building construction in urban areas. The problem of the impact of highrise building construction in big cities on the living environment is considered. Using analytical methods, causes and sources of pollution, such as transport and engineering infrastructure have been identified. In some urban areas, there are zones with modified thermal conditions and air exchange resulting in the formation of the "urban heat island"The qualitative and quantitative characteristics of variations in temperature and wind speed with respect to the height of the building have been calculated, using the example of the Evolution Tower of the Moscow International Business Center ("Moscow City"). Calculation and comparative analysis for the cities of Moscow, Khanty-Mansiysk and Vladivostok has made it possible to assess the variation in temperature and wind speed and their impact on the living environment under different climatic conditions.
\end{abstract}

\section{Introduction}

The rapid growth of the economy of the leading countries is contributing to the development of big cities. In connection with intensive internal and external migration of people to big cities, the population density is increasing. As a result, the number of modern multi-storey buildings and high-rise buildings is increasing, and the engineering and transport infrastructure is developing at an incredible pace. A modern metropolitan area is a living environment that combines a natural environment, a high-tech production environment, an intensive transport environment, a recreation environment and a highdensity residential environment.

\footnotetext{
${ }^{*}$ Corresponding author: dandyr@mail.ru
} 
The growth of modern high-rise buildings significantly affects the existing climatic conditions of the terrain and the environmental balance of the living environment. At the same time, the density of urban development, the infrastructure and transport networks play an important role in changing the living environment. Urban development as a combination of complex architectural forms significantly affects the aerodynamics of the terrain. In this regard, both industrial areas and high-density residential areas are environmentally unfavorable. Thus, high-rise buildings and structures, being an integral part of a modern city, significantly aggravate the environmental conditions of urban areas.

One of the important components of the living environment of a city is the residential environment. The unified system "man - apartment - building - neighborhood - residential area of the city" defined in the scientific literature as "residential environment" has complex features and mechanisms. A human being, interacting with the residential environment, performs non-productive activities on the territory of populated areas. In big cities, the development of the living environment, mainly consisting of multi-storey buildings, high-rise buildings and modern public spaces, causes variation in temperature and wind conditions of the terrain and aggravates the environmental situation [4].

High-density residential areas of the city, being the most important part of any metropolitan area, where comfortable living conditions are created for their residents, are exposed to the constant impact of pollution sources. The main sources of air pollution in residential areas include industrial enterprises, heating boiler houses and road transport. The economic growth and the increasing pace of construction of high-rise residential buildings, public and business centers in big and metropolitan cities, have resulted in an increase in business activity and use of motor transport. Motor transport as a mobile source of pollution is the main source of air pollution in residential areas. Due low location and close proximity to the residential area, motor vehicles create extensive and stable zones of pollution, with the concentration of pollutants in the air exceeding the permissible level by several times.

A modern city with high-rise buildings is a fairly effective system of heating the vertical surfaces of buildings and horizontal surfaces of roofs, sidewalks and roads with solar heat [8]. At the same time, the high-density construction of certain areas hinders natural aeration and causes the formation of urban heat islands that affect the pollution of the air basin. (Fig. 1) $[10]$.
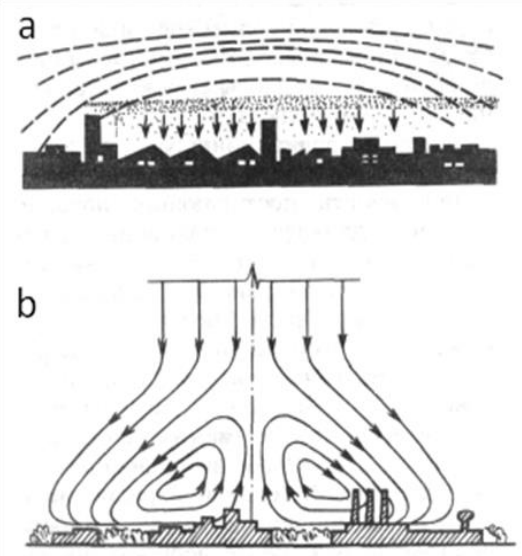

Figure. 1. "Urban heat island" formation: a - dissipation of industrial emissions in the "urban heat island" (deep surface inversion); b - circulation in the lower atmosphere over the city. 
In addition, the environmental situation is negatively affected by the stagnation of air masses caused by natural and climatic factors, such as no-wind conditions, surface temperature inversion (Fig. 2) [10]. Temperature inversion in some regions can occur throughout the year.

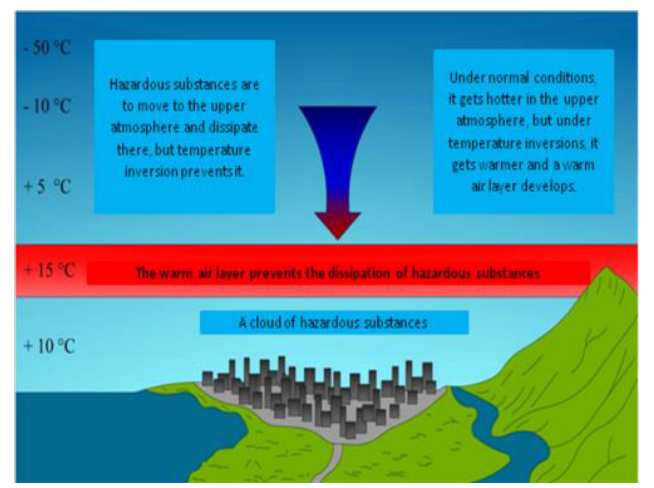

Fig. 2. Surface inversion of temperature.

Public space in residential areas is a living environment and one of the most important parts of the city's air basin. The natural wind regime in public residential areas of a modern city is affected by high density of high-rise buildings, and the air has a higher concentration of pollutants due to lack of the air exchange. Getting into the lungs of urban residents together with the inhaled air, pollutants modify gas exchange and cause oxygen starvation, thereby causing asthma or its aggravation and other lung diseases. Thus, the issue of aeration of areas with high-rise buildings is becoming increasingly important. In this regard, the most interesting are the convective currents that arise when the temperature difference between the surfaces of facades of buildings and public spaces.

In the city, the differences in the heating of open and shaded sections of streets and public space influence the local air circulation. Ascending flows concentrate above the surface of the walls exposed to light, and descending flows concentrate above the shaded walls [3]. The presence of water bodies in the cities contributes to the development of local circulation from the water body to the urban areas at daytime, and in the opposite direction at night. The speed of air flows at the outer surface of buildings, due to the difference in the temperatures of the surface of the enclosing structure and the outside air, can reach up to 10 $\mathrm{m} / \mathrm{s}$ and plays an important role in the air exchange of the adjacent space (Fig. 3) [1]

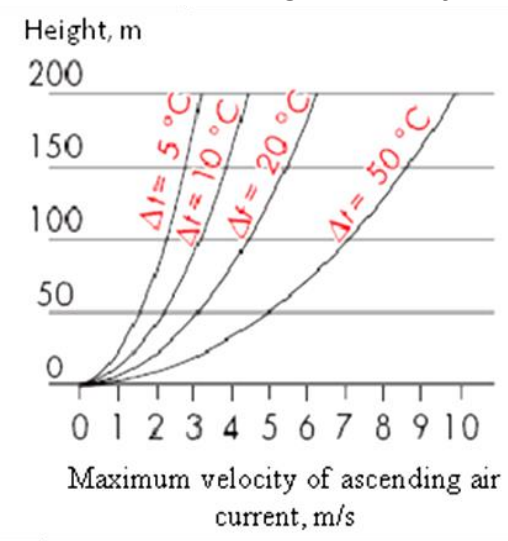

Fig. 3. Dependence of the speed of ascending flows on the height. 
In the warm period of the year, the temperature of the exterior surfaces of buildings increases sharply due to irradiation with solar radiation and differs significantly from the outside air temperature. The temperature difference contributes to the formation of convective heat flow directed up the building, resulting in the emergence of the so-called near-surface (boundary) layer of heated air, (Fig. 4) [1,7,9]

The amount of solar radiation and the coefficient of solar radiation absorption by the material of the outer surface of the enclosing structures creates a temperature difference between the external surface of the building and the surrounding air.

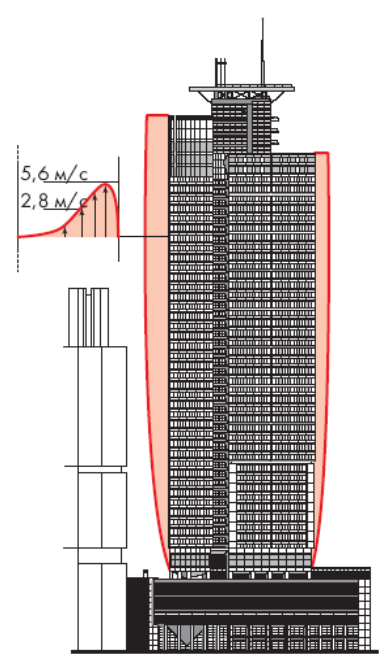

Fig. 4 An example of the velocity profile of ascending air currents at the outer surface of a high-rise building due to the effect of a temperature difference $\mathrm{Dt}=20^{\circ} \mathrm{C}$.

\section{Materials and Methods}

The analysis and the study of the Moscow City International Business Center revealed that compactly located towers have transformed the wind regime of the area. The rapidly developing transport and engineering infrastructure seriously exacerbates the environmental situation. Due to the density of the high-rise buildings, the Moscow City Business Center and the intensity of transport communication on the territory, there appeared extensive stable zones with stagnation of the air, where wind speeds range from 0 to $1 \mathrm{~m} / \mathrm{s}$. Thus, the territory of the Moscow City Business Center has created its own local climate, with its specific microclimatic conditions on its streets and squares. This microclimate is determined by high-rise urban development. According to our research, the formation of local microclimatic conditions is facilitated by a change in the height of buildings, air temperature and wind speed.

Using the example of the Evolution Tower, the calculation of the temperature of the outside air, atmospheric pressure and wind speed depending on the height of the building has been made.

The variation in the outside air temperature and atmospheric pressure depending on the building height can be determined by the following formulas [3]:

$$
t_{h}=t_{0}-0,0065 \times h,{ }^{0} \mathrm{C}
$$




$$
p_{h}=p_{0}\left(1-2,25577 \times 10^{-5} \times h\right)^{5,2559}, P a
$$

where $t_{h}, p_{h}$ is temperature, ${ }^{\circ} \mathrm{C}$, and pressure, $\mathrm{Pa}$, at the height $\mathrm{h}, \mathrm{m}$, respectively; $t_{0}, p_{0}$ is temperature, ${ }^{\circ} \mathrm{C}$, and pressure, $\mathrm{Pa}$ at the earth's surface, respectively.

\section{Results}

The calculated climatic parameters according to [4] are determined for the cities of Moscow, Khanty-Mansiysk and Vladivostok.

Using the data obtained, the graphs of the variation in the outside air temperature along the height of the building are constructed (Fig. 5,6).

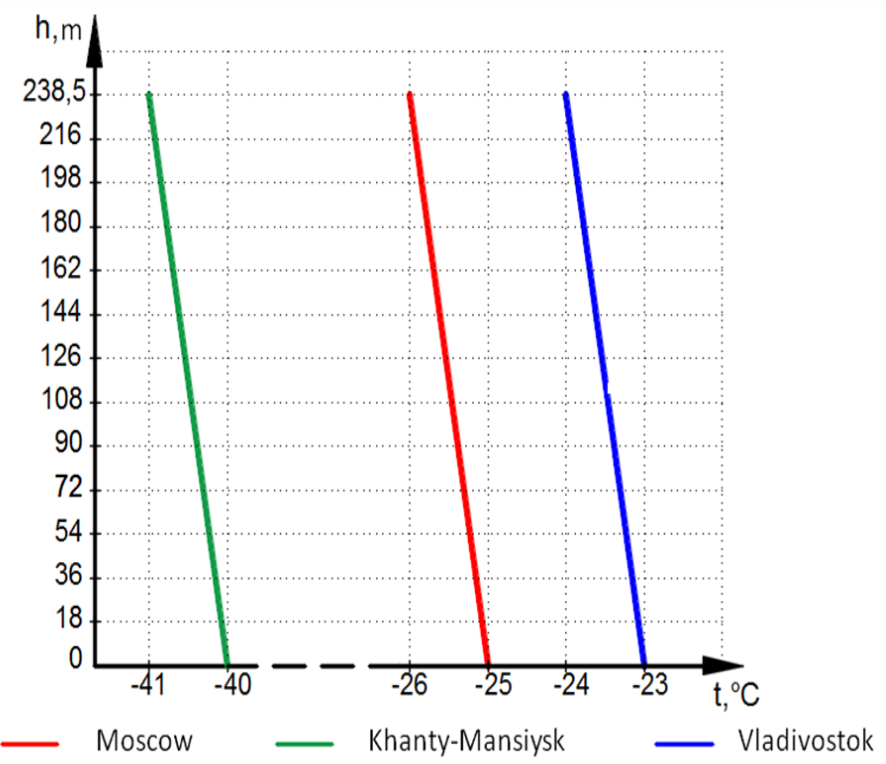

Fig. 5 - Variation in the air temperature depending on the height of the Evolution Tower during the coldest five-day period for the cities of Moscow, Khanty-Mansiysk and Vladivostok.

Various models are used to estimate the variation in the wind speed with respect to the height: the Ekman spiral, the logarithmic law, the power law. $[5,6]$ These models estimate the wind speed $V$ at height $h$ if the wind speed $V_{0}$ is known at height $h_{0}$.

The power law of variation of the wind speed with respect to height has the form $[5,6]$ :

$V_{h}=V_{0}\left(h / h_{0}\right)^{a}, \mathrm{~m} / \mathrm{s}(2.3)$

where $V_{h}$ is wind speed, $\mathrm{m} / \mathrm{s}$, at height $h, \mathrm{~m}$;

$V_{0}$ is wind speed, $\mathrm{m} / \mathrm{s}$, changing at the height $h_{0}, \mathrm{~m}$ (wind speeds are measured at a height of $10-15 \mathrm{~m}$, therefore $h_{0}=10-15 \mathrm{~m}$ );

$\alpha$ is exponent depending on the type of terrain and found experimentally; it is recommended for centers of large cities to take $\alpha=0,33$, for suburban areas $\alpha=0,22$, for open space $\alpha=0,14$ [6]. 


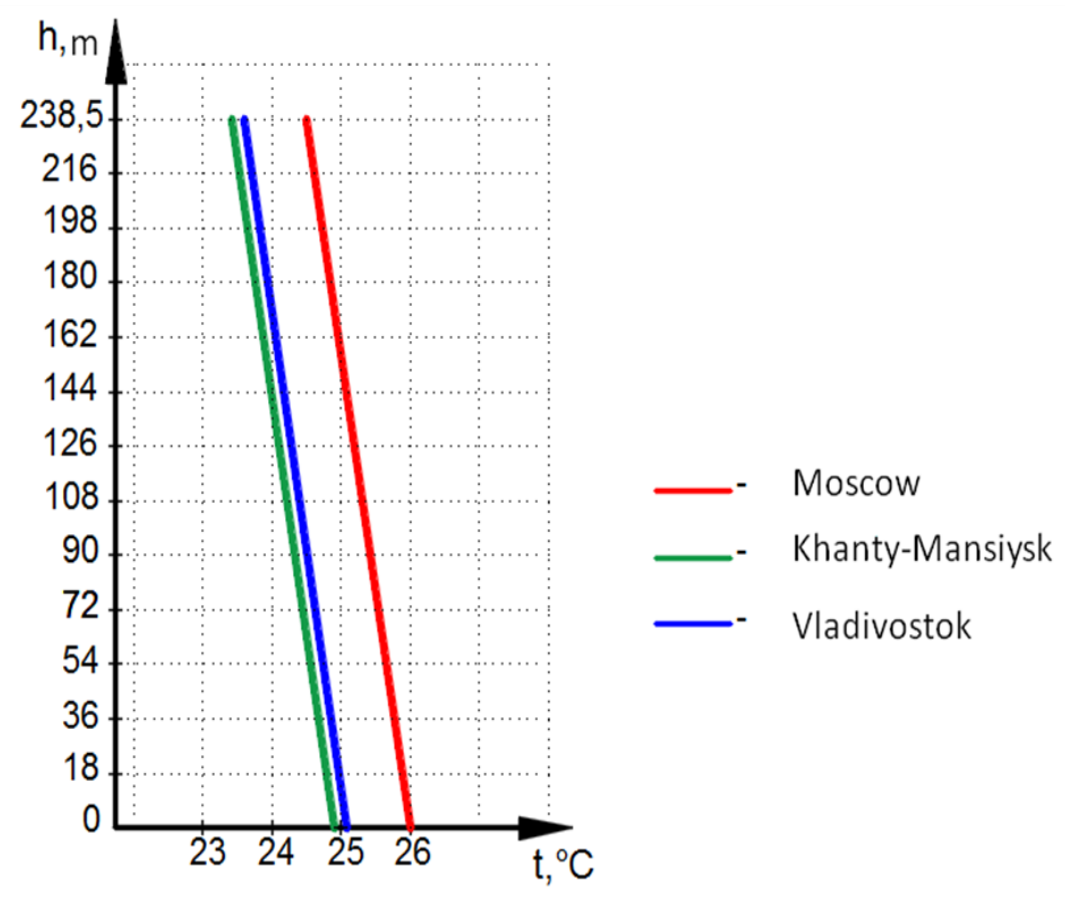

Fig. 6 Variation in the air temperature depending on the height of the Evolution Tower during the warm period for the cities of Moscow, Khanty-Mansiysk and Vladivostok.

The values of wind speed at a height of $10 \mathrm{~m}$ are assumed to be equal to the values from Tables 3.1 and 4.1 [4], for the city of Moscow for the warm and cold periods of the year. Based on the results of the calculation, a graph of the variation in wind speed with respect to the height of the building was constructed (Fig.7)

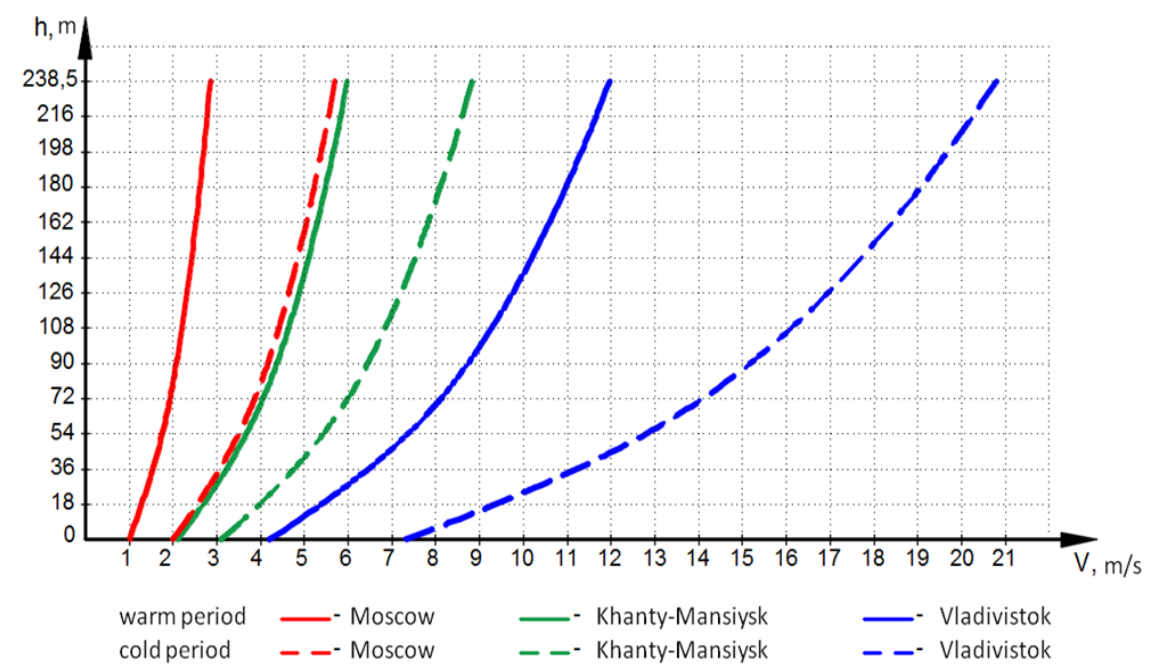

Fig. 7 Variation in the wind speed with respect to the height of the Evolution Tower the cities of Moscow, Khanty-Mansiysk and Vladivostok 
As can be seen from Fig.7, with the increasing height of the building, the wind speed increases and in urban development areas this occurs more intensively.

\section{Conclusions}

From the findings of the study, the following conclusions can be drawn:

1. Modern urban areas with high-rise buildings have an impact both the local aerodynamics and the temperature conditions of the territory. As a result, environmentally unfavorable zones with stagnant air develop in public open spaces.

2. High-rise buildings in urban areas, being an effective system of solar heating of the vertical surfaces of buildings and horizontal surfaces of roofs, sidewalks and roads, accumulate heat and result in the formation of urban heat islands.

3. When designing high-rise buildings, it is necessary to take into account the specifics of the built-up areas, the spatial plasticity and the density of construction, which affect the aerodynamics of the terrain and the pollution of the atmospheric air.

4. The calculations and studies made it possible to evaluate the impact of high-rise buildings on the microclimate and the environmental conditions. The variation in wind speed with respect to the height of the building, the formation of ascending convective flows at the outer surface of a high-rise building are the factors that can improve the environmental situation and the microclimate of the living environment.

\section{References}

1. Ju. A. Tabunshhikov, N. V. Shilkin Ajerodinamika vysotnyh zdanij (AVOK, 2004)

2. B.I. Gijasov, Vestnik MGSU 3, 13-15. (2012)

3. B.I. Gijasov, Vestnik MGSU 4, 17-21. (2012)

4. Russian Standard SP 131.13330.2012.

5. Je.Simiu, R.Scanlon, The impact of wind on buildings and structures (Strojizdat, 1984)

6. ASHRAEHandbook. Fundamentals. SIEdition,1997.

7. Ju. A.Tabunshhikov, M. M.Brodach, N. V. Shilkin. Energy efficient buildings (AVOK-PRESS, 2003)

8. E.G. Maljavina, S.V.Birjukov. Calculation of the air regime of multi-storey buildings with different air temperatures inside the buildings, AVOK, 2 (2008)

9. O.D. Samarin. Zhilishhnoe stroitel'stvo, 1, 32 - 33. (2013)

10. S.P. Hromov, M.A. Petrosjanc. Meteorologija i klimatologija. (Nauka, 2006) 